\title{
Corrigendum
}

\section{The Serotonin 5-HT2A Receptors Antagonist MI00907 Prevents Impairment in Attentional Performance by NMDA Receptor Blockade in the Rat Prefrontal Cortex}

Mirjana Carli, Marta Baviera, Roberto W Invernizzi and Claudia Balducci

Neuropsychopharmacology (2004) 29, 2300. doi:I 0.I038/sj.npp. I 300545

Correction to: Neuropsychopharmacology (2004) 29, 16371647. doi:10.1038/sj.npp.1300479.

Following publication of the above paper, the author has identified an error with the name of one of the authors. Dr Carli's name is now correctly represented above. 